\title{
Oral Cancer Awareness in Turkish Dental Patients
}

\author{
D Kader Cesur Aydın, (D) Aslıhan Akbulut \\ Department of Dentomaxillofacial Radiology, İstanbul Medipol University, Faculty of Dentistry, Istanbul, Turkey
}

\section{ABSTRACT}

Objectives: This study aims to provide data from dental patients about their oral health attitudes, dental visits, oral cancer predisposing factors and general knowledge about early signs of oral cancer.

Methods: This study was conducted on dental examination patients, involving both genders with an age range of 12-77 years. All questions were asked through a written questionnaire.

Results: This study included 254 cases with a mean age of $31.8 \pm 16.4$ years. One hundred and fifty three (60.2\%) of the study group consisted of females and 101 (39.8\%) were males. Smoking and alcohol consumption were frequent among the working group and males $(p=0.001)$. Regarding general knowledge about early cancer signs, there was no significance among genders. Considering attitudes of the last dental visits of individuals according to their occupation, the working group displayed significance $(p=0.005)$. The total rate for information about oral cancer, causes and symptoms 20 (7.9\%) individuals had positive knowledge. Only $5(0.02 \%)$ of the participants would refer to a dentist for neck swelling.

Conclusion: General knowledge of signs and symptoms of oral cancer are low in Turkish dental patients, most declare that early diagnosis is important. The main predisposing factors of oral cancer (smoking and alcohol) are statistically more consumed by the working group but showed no gender predisposition.

Please cite this article as: Cesur Aydın K, Akbulut A. Oral Cancer Awareness in Turkish Dental Patients. Anatol J Family Med 2020;3(1):64-70.

Address for correspondence: Dr. Kader Cesur

Aydın. Department of Dentomaxillofacial Radiology, İstanbul Medipol University, Faculty of Dentistry, Istanbul Turkey

Phone: +90 5327952657

E-mail: kadercesur@yahoo.com

Received Date: 16.07.2019

Accepted Date: 18.09.2019

Published online: 01.04 .2020

(C) Copyright 2020 by Anatolian Journal of Family Medicine Available online at www.anatoljfm.org

Keywords: Early diagnosis, oral cancer, smoking

\section{INTRODUCTION}

Oral cancer is a common disease entity among all parts of the world, which accounts for $3-5 \%$ of all tumors. ${ }^{[1]}$ The area of the head and neck is studied as a single topic as oral cancer due to epidemiological studies involving oral, nasopharyngeal and laryngeal cancer types display similar outcomes. The main causes in aetiology are tobacco and alcohol usage in $90 \%$ of the cases, as well as genetic background, personal exposures and oncogenic virus contamination have a considerable impact. ${ }^{[2-4]}$ By reducing tobacco and alcohol usage mostly in public common places and providing cessation support, public health initiatives are contributing to the prevention of the malignancies. ${ }^{[5-6]}$

Common symptoms of oral cancers may include red/white lesions that are regarded as potentially malignant disorders, oral ulcers/pharyngitis, swelling of the mouth/neck, numbness of the perioral area and bloody postnasal drainage for a prolonged time period. ${ }^{[7-9]}$ Adjunctive screening aids, as well as conventional intraoral examination, play a significant role in early diagnosis and management. ${ }^{[10]}$ Many clinical branches in medicine, as well as dentistry, may contribute to the access of oral cancer diagnosis.

Early diagnosis and efficient treatments help survive oral cancer; thus, knowledge about the signs and symptoms has a key role in society. This article aims to provide data from den- 
tal patients about their oral health attitudes, dental visits, oral cancer predisposing factors like smoking, alcohol consumption and genetic susceptibility; and general knowledge about early signs of oral cancer as well as detecting first referral place in case of major cancer finding like neck swelling occurred. It is estimated that, through asking these questions, awareness of oral cancer risk factors, signs and symptoms may be formed as a behavioral change, as an initial step to avoid them.

\section{METHOD}

This study was conducted as a written questionnaire for individuals who referred for dental examination during JanuaryFebruary 2018; with an age range of 12-77 years, involving both genders. The survey was based on three sections. $1^{\text {st }}$ section included demographic data, $2^{\text {nd }}$ section inquired oral health status and predisposing factors for oral cancer (smoking/ alcohol/genetic background) and $3^{\text {rd }}$ section surveyed general knowledge about the causes/symptoms of oral cancer and first place of referral if any symptoms existed. This study was conducted upon approval of Istanbul Medipol University Ethical Committee of Non- Interventional Clinical Researches (Conclusion Number 319).

Independent variables of the questionnaire include age, gender, occupational status, smoking, type of smoked product, weekly alcohol consumption, family members treated for cancer, recovery time in oral ulcers, red/ white areas in the mouth, burning mouth, numbness around the mouth, prolonged pharyngitis, neck swelling, bloody post-nasal drainage and prolonged nasal congestion, information about oral cancer, causes and symptoms, importance of early diagnosis for the treatment of cancer, last visit time to the dentist and first place of referral for swelling in the neck. All questions were asked by the examiner dentist, through the written questionnaire, keeping patients at separate rooms.

While assessing the findings obtained in this study, IBM SPSS Statistics 22 (IBM SPSS, Turkey) was used for the statistical analysis. Compliance with parameters to distribution was evaluated using the Shapiro Wilks test, and parameters were determined to be suitable to a normal distribution. While evaluating the study data, descriptive statistical methods (mean, standard deviation, frequency) were used. Chi-square test, Fisher's Exact Chi-square test and Continuity (Yates) Correction was used for the comparison of qualitative data. $P<0.05$ was set as the level of significance.

\section{RESULTS}

This study demographics in the $1^{\text {st }}$ section included 254 cases with a mean age of $31.8 \pm 16.4$ years; 101 (39.8\%) males and 153 (60.2\%) females. The occupational status of this study group revealed that 100 (39.4\%) of cases were working, 78 (30.7\%) were non-working, 56 (22.0\%) were students, and 20 (7.9\%) did not answer this question.

The second section of the questionnaire inquired about oral health status and predisposing factors for oral cancer like smoking, alcohol consumption and family history; Table 1 displays the outcomes. Smoking was classified as always, sometimes, never and quit consumption and the rates were 51 (20.1\%), 30 (11.8\%), 147 (57.9\%) and 26 (10.2\%) respectively. Mean number of smoked material was 10.5 (1.040.0). One hundred forty seven (57.9\%) of the participants never smoked. The type of material smoked among previous and present smokers was as follows: filtered cigarettes 101 (39.8\%), unfiltered cigarettes 3 (1.2\%), cigar 1 (0.4\%), other $2(0.8 \%)$ and none 147 (57.9\%). The results of weekly alcohol consumption displayed that 148 (58.3\%) never consumed alcohol, 37 (14.6\%) did not consume at the moment, 28 (11.0\%) consumed 1-3 glasses a week, 5 (2.0\%) consume 4-7 glasses weekly, 3 (1.2\%) consumed more than eight glasses, and 33 (13.0\%) of the cases did not answer the question. Eighty five (33.5\%) of the cases had relatives treated for cancer, $163(64.2 \%)$ of them did not have any

\section{Table 1. Predisposing factors for oral cancer}

\begin{tabular}{|c|c|c|}
\hline & $\mathbf{n}$ & $\%$ \\
\hline \multicolumn{3}{|l|}{ Smoking } \\
\hline Yes & 51 & 20.1 \\
\hline Sometimes & 30 & 11.8 \\
\hline No, never have & 147 & 57.9 \\
\hline No, stopped consuming it & 26 & 10.2 \\
\hline \multicolumn{3}{|l|}{ Type of product smoked } \\
\hline Filtered cigarette & 101 & 39.8 \\
\hline Unfiltered cigarette & 3 & 1.2 \\
\hline Cigar & 1 & 0.4 \\
\hline Other & 2 & 0.8 \\
\hline Non-smoker & 147 & 57.9 \\
\hline \multicolumn{3}{|l|}{ Alcohol consumption (weekly) } \\
\hline Never & 148 & 58.2 \\
\hline Not consuming at the moment & 37 & 14.6 \\
\hline 1-3 glasses a week & 28 & 11.0 \\
\hline 4-7 glasses a week & 5 & 2.0 \\
\hline 8 and more glasses a week & 3 & 1.2 \\
\hline Unanswered & 33 & 13.0 \\
\hline \multicolumn{3}{|l|}{ Family members treated for cancer } \\
\hline Yes & 85 & 33.5 \\
\hline No & 163 & 64.2 \\
\hline Unanswered & 6 & 2.4 \\
\hline
\end{tabular}


cancer history and $6(2.4 \%)$ of the individuals did not answer the question.

Distribution of smoking, according to the profession, was found statistically significant $(p=0.001)$. Bilateral comparative studies showed that there was a statistical significance for smoking among the working cases and non- working cases/students $(p=0.001)$. There was no statistical difference in smoking between non- working cases and students ( $p=0.088$ ). Consumption of alcohol, according to the profession, was found statistically significant $(p=0.001)$. Bilateral comparative studies revealed that there was a statistical difference in alcohol consumption between working cases and not-working cases/students $(p=0.001)$. There was no statistical difference for the consumption of alcohol between non- workers and students $(p=0.210)$.

Evaluation of smoking and alcohol consumption among genders revealed no statistical significance $(p=0.001)$.

The third section surveyed general knowledge about the causes/symptoms of oral cancer and first place of referral if any symptoms existed. The survey included questions about the current and prolonged oral mucosal status of the individuals, also early signs of oral cancer, and displayed in Table 2.

Regarding the recovery period of oral ulcers, 89 (35.1\%) of the cases answered 2-3 days, 79 (31.1\%) answered 4-5 days, 47 (18.5\%) one week, and 9 (3.5\%) answered 15 days and 30

Table 2. Oral health status of the patients according to gender

\begin{tabular}{|c|c|c|c|}
\hline & & & \\
\hline & $\begin{array}{c}\text { Female } \\
\text { n (\%) }\end{array}$ & $\begin{array}{l}\text { Male } \\
\text { n (\%) }\end{array}$ & p \\
\hline Recovery time & & & \\
\hline $2-3$ & $53(40.2)$ & $36(39.1)$ & $0.175^{*}$ \\
\hline $4-5$ & $40(30.3)$ & $39(42.4)$ & \\
\hline 7 & $33(25.0)$ & $14(15.2)$ & \\
\hline 15 & $6(4.5)$ & $3(3.3)$ & \\
\hline White or red ar & & & \\
\hline Yes & 41 (27.7) & 21 (21.6) & $0.287^{*}$ \\
\hline No & $107(72.3)$ & $76(78.4)$ & \\
\hline Complaint of $b$ & & & \\
\hline Yes & $10(6.7)$ & $1(0.1)$ & $0.100^{*}$ \\
\hline No & $127(84.7)$ & $90(90.9)$ & \\
\hline Sometimes & $13(8.7)$ & $8(8.1)$ & \\
\hline Numbness of $n$ & & & \\
\hline Yes & $14(9.3)$ & $5(0.5)$ & $0.296^{* *}$ \\
\hline No & $136(90.7)$ & $96(0.95)$ & \\
\hline Swelling in mo & & & \\
\hline Yes & $19(13.1)$ & $12(12.1)$ & $0.976^{* *}$ \\
\hline No & $126(86.9)$ & $87(87.9)$ & \\
\hline Prolonged pha & & & \\
\hline Yes & $19(12.8)$ & $9(9.1)$ & $0.480^{* *}$ \\
\hline No & $129(87.2)$ & $90(90.9)$ & \\
\hline Neck swelling & & & \\
\hline Yes & $6(4.0)$ & $3(3.0)$ & $1.000^{* * *}$ \\
\hline No & $144(96.0)$ & $96(97.0)$ & \\
\hline Bloody post-na & & & \\
\hline nasal congestic & & & \\
\hline Yes & $28(18.9)$ & $12(12.1)$ & $0.213^{* *}$ \\
\hline No & $120(81.1)$ & 87 (87.9) & \\
\hline
\end{tabular}


(11.8\%) of the cases did not answer the question. Regarding cases with red or white areas in their mouth or on their gums 62 (24.4\%) were positive, whereas 183 (72.0\%) did not have any macular lesions; 9 (3.5\%) of the cases did not answer the question. Regarding burning mouth symptoms, 11 (4.3\%) of the cases always had burning mouth complaints, and 21 (8.3\%) sometimes had burning mouth complaints. Regarding numbness in the perioral area, $19(7.5 \%)$ of the cases had numbness in/ around the oral area and of the cases had prolonged pharyngitis; 31 (12.2\%) of the cases had swelling in the mouth; 9 (3.5\%) of the cases had swelling in the neck, and $40(15.7 \%)$ of the cases had bloody postnasal drainage or prolonged nasal congestion. Regarding all early cancer signs, there is no statistical significance among genders (Table 2). There was statistical significance for last dental visit time according to the profession $(p=0.005)$. The Chi-square test results revealed no statistical significance for working and non-working cases $(p=0.112)$. Statistical significance was found between workers and students $(p=0.047)$, as well as students and non-workers $(p=0.006)$. Attitudes of last dental visits of individuals according to their occupation can be seen in Figure 1b.

Figure 1a reveals the last dental referral period of the individuals for evaluation of the oral health status.

Regarding information about oral cancer causes, symptoms and importance of early cancer diagnosis, there was no statistical significance among professions $(p=0.053)$. Table 3 displays the evaluation of early oral cancer signs knowledge according to the occupation, and Table 4 displays the evaluation of early oral cancer signs knowledge according to gender. There was no statistical significance for both surveys. The total rate for information about oral cancer, causes and symptoms had 20 (7.9\%) positive knowledge; and about the importance of early diagnosis for the treatment of cancer study group revealed 234 (92.1\%) positive results in total.

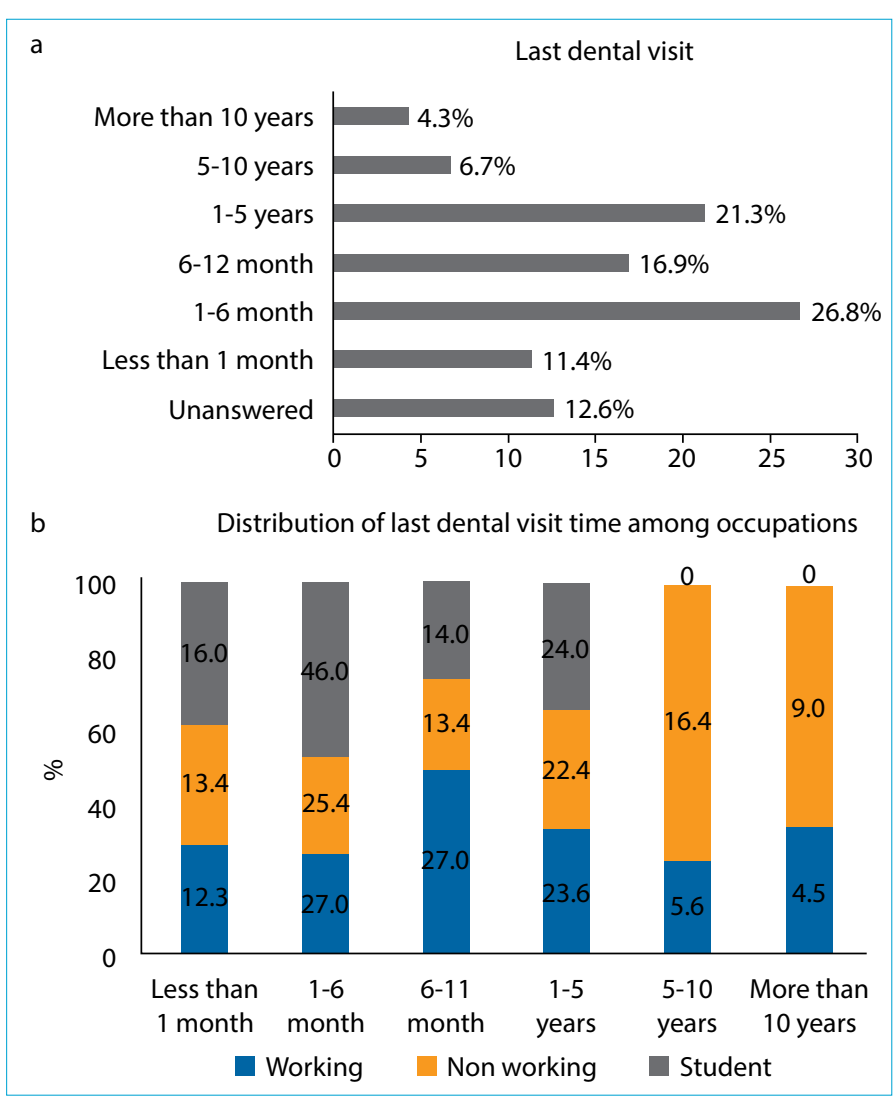

Figure 1. (a) Last visit to the dentist/oral health status; (b) Distribution of last dental visit time among occupations/oral health status.

Figure 2 reveals the percentages that the individuals would refer initially to swelling of the neck and 89 (35.0\%) of the patients did not know where to refer and $63(24.8 \%)$ referred to ENT (Ear Nose Throat Specialist) and only 5 (2.0\%) referred to a dentist.

Regarding gender as a variant, significant excess was found in the usage of mouthwash in women compared to men $(p=0.015)$. All other questions revealed non-significant results among genders ( $p>0.05)$.

Table 3. Evaluation of the early oral cancer signs knowledge according to occupation

\begin{tabular}{|c|c|c|c|c|}
\hline & $\begin{array}{c}\text { Working } \\
\text { n (\%) }\end{array}$ & $\begin{array}{c}\text { Non-working } \\
\text { n (\%) }\end{array}$ & $\begin{array}{c}\text { Student } \\
\text { n (\%) }\end{array}$ & $\mathbf{p}$ \\
\hline \multicolumn{5}{|c|}{ Information about oral cancer, causes and symptoms } \\
\hline Yes & $6(6.2)$ & $4(5.3)$ & $9(16.1)$ & 0.053 \\
\hline No & $91(93.8)$ & 71 (94.7) & 47 (83.9) & \\
\hline \multicolumn{5}{|c|}{ Is early diagnosis important for the treatment of cancer? } \\
\hline Yes & 94 (96.9) & $70(92.1)$ & $53(96.4)$ & 0.307 \\
\hline No & $3(9.1)$ & $6(7.9)$ & $2(3.6)$ & \\
\hline
\end{tabular}


Table 4. Evaluation of the early oral cancer signs knowledge according to gender

\begin{tabular}{|c|c|c|c|}
\hline & \multicolumn{2}{|c|}{ Gender } & \multirow[t]{2}{*}{ p } \\
\hline & $\begin{array}{c}\text { Female } \\
\text { n (\%) }\end{array}$ & $\begin{array}{l}\text { Male } \\
\text { n (\%) }\end{array}$ & \\
\hline \multicolumn{4}{|c|}{ Information about oral cancer, causes and symptoms } \\
\hline Yes & $13(8.8)$ & $7(7.1)$ & 0.824 \\
\hline Yes & $142(95.3)$ & $92(93.9)$ & \multirow[t]{2}{*}{0.842} \\
\hline No & $7(4.7)$ & $6(6.1)$ & \\
\hline
\end{tabular}

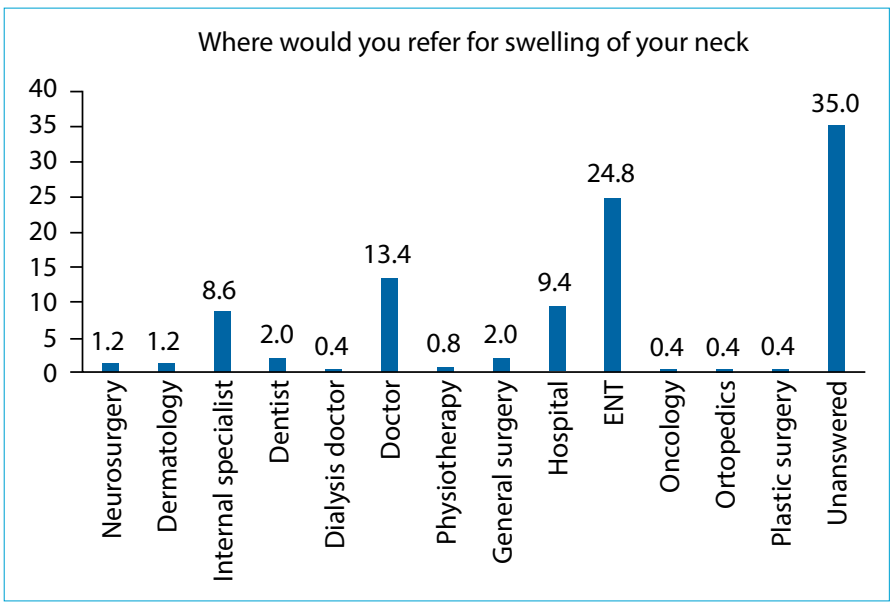

Figure 2. The first place of the referral for the swelling in the neck.

\section{DISCUSSION}

Occupational status revealed that $39.4 \%$ of the cases are working, $30.7 \%$ are not working, and $22 \%$ are students. Both daily smoking and weekly alcohol consumption of the individuals considering occupational status revealed that the working group had more consumption than the non-working and student groups. $90 \%$ of oral cancer cases are due to smoking and alcohol consumption. ${ }^{[11,12]}$ It can be estimated that the working group is more predisposing factors for oral cancer.

Recent studies reveal that males are more susceptible to oral cancer than females, on the other hand, our study group displayed no statistical significance for smoking and alcohol consumption among males and females, displaying no accordance for gender predisposancy. ${ }^{[13,14]}$

The incidence of oral cancer in younger age individuals under age 45 complies $6 \%$ of all cases. ${ }^{[15]}$ Our study group also revealed that the working group is more predisposing fac- tors to oral cancer due to increased smoking and alcohol consumption.

Independent from smoking and alcohol, family history among first- degree relatives is a strong determinant of oral and pharyngeal cancer risk. ${ }^{[16]}$ Our study group revealed that $33.5 \%$ of all subjects had cancer diagnosis of any type of first-degree relatives, which also increases the risk of recalling the disease. The elevated risks in genetic predisposancy in familial cancers may also be due to shared environmental exposure. ${ }^{[17]}$

Prolonged oral ulcers are mainly the initial symptom of oral cancer according to researchers. ${ }^{[18-19]}$ To call public attention to recovery times of oral ulcers and risks arising from prolonged ulcers, our study involved the question 'How many days it takes for oral ulcers to heal?'; $35 \%$ of individuals answered $2-3$ days, $31.1 \%$ answered $4-5$ days, $18.5 \%$ answered seven days, and $3.5 \%$ answered 15 days as normal healing times. A previous study on Turkish patients by Peker and Alkurt revealed that $79.2 \%$ of the participants were unaware of the early signs related to oral cancer ${ }^{[20]}$ Considering proper healing times in oral ulcers as 7 days, only $3.5 \%$ of our study group has misknowledge for an early sign of oral cancer. $24.4 \%$ of the patients had red/ white areas in their mouth, $4.3 \%$ had a burning mouth, $7.5 \%$ had numbness around the mouth, $12.2 \%$ had swelling in the mouth, $11 \%$ had prolonged pharyngitis, $3.5 \%$ had neck swelling and $15.7 \%$ had bloody post-nasal drainage/prolonged nasal congestion. These individual results are displayed both as oral health status and revealings of early oral cancer signs, and none are as high as the previous study. ${ }^{[20]}$

About the importance of early diagnosis for the treatment of cancer, $92.1 \%$ revealed positive answers. Regarding information about oral cancer causes and symptoms, 7.9\% 
of the study group had positive knowledge. This result is also in harmony with studies revealing participants were unaware of the early signs related to oral cancer in Turkish society and Northern German Society; on the other hand, has bias with Srikanth et al. who surveyed for the Indian society. ${ }^{[19-21]}$ Srikanth et al. also stated that women had better knowledge about oral cancer findings, although our study had no difference among genders. ${ }^{[21]}$

Individuals' last dental referral period to the dentist has a considerable impact on oral health attitudes and also has implications on early diagnosis. Only $38.2 \%$ of the patients attended the dental examinations in the last six months when this study was conducted. These are valuable data concerning the importance of early diagnosis in oral signs. Hertrampf et al. presented that $66 \%$ of oral cancer lesions were most often diagnosed at an advanced-stage, as our study group revealed $61.8 \%$ of the patients attended the irregular and long period dental examination. ${ }^{[19]}$ Our study group also revealed no difference in the last dental referral periods among genders. Groupings according to occupational status display that working group have earlier examination periods than students; and students have earlier dental examination periods than non-workers.

The question of first referral place for a neck swelling' was asked to detect patients' dentist perceptions about an oral cancer diagnosis. The results revealed that only $2 \%$ would prefer a dental examination, and $24.8 \%$ would go to an ENT specialist, while $35 \%$ had no answer. This result also suggests that $35 \%$ have no knowledge about the initial examination and early management of oral cancer. Given that the disease is orofacial related, $2 \%$ that would apply a dentist for oral cancer diagnosis is a relatively low rate. Although many non-invasive examination methods like fluorescent light examination and toluidine blue applications are easily performed for early oral cancer diagnosis in the daily practice of dentistry, many lesions are cured by surgical interventions due to advanced-stage diagnosis. ${ }^{[22,23]}$ While computerized tomography and magnetic resonance imaging are generally accessible in medical clinics, it may cause an interpretation of the patients that diagnosis may hardly be made by the dentists.

\section{CONCLUSION}

General knowledge of signs and symptoms of oral cancer are low in Turkish dental patients. Most declare that early diagnosis is important. Main predisposing factors of oral cancer (smoking and alcohol) are statistically more consumed by the working group but showed no gender predisposition. Oral health status findings reveal that the study group has decreased risks of developing oral cancer.
Although dental patients are selected for an interview, only $2 \%$ stated to go to a dentist for diagnosis of neck swelling.

\section{Disclosures}

Peer-review: Externally peer-reviewed.

Conflict of Interest: None declared.

Ethics Committee Approval: This study was conducted upon approval of Istanbul Medipol University Ethical Committee of Non- Interventional Clinical Researches (Conclusion Number 319; Date 08.16.2016).

Authorship Contributions: Concept - K.C.A.; Design - K.C.A.; Supervision - K.C.A.; Materials - K.C.A.; Data collection \&/or processing - K.C.A., A.A.; Analysis and/or interpretation - K.C.A., A.A.; Literature search - K.C.A., A.A.; Writing - K.C.A.; Critical review K.C.A., A.A.

\section{REFERENCES}

1. Baykul T, Yilmaz HH, Aydin U, Aydin MA, Aksoy M, Yildirim D. Early diagnosis of oral cancer. J Int Med Res 2010;38(3):73749. [CrossRef]

2. Blot WJ, McLaughlin JK, Winn DM, Austin DF, Greenberg RS, Preston-Martin $S$, et al. Smoking and drinking in relation to oral and pharyngeal cancer. Cancer Res 1988;48(11):3282-7.

3. Dissanayaka WL, Pitiyage G, Kumarasiri PV, Liyanage RL, Dias KD, Tilakaratne WM. Clinical and histopathologic parameters in survival of oral squamous cell carcinoma. Oral Surg Oral Med Oral Pathol Oral Radiol 2012;113(4):518-25. [CrossRef]

4. Nowosielska-Grygiel J, Owczarek K, Bielińska M, Wacławek $M$, Olszewski J. Analysis of risk factors for oral cavity and oropharynx cancer in the authors' own material. Otolaryngol Pol 2017;71(2):23-8. [CrossRef]

5. Cergibozan R. Testing for the Rational Addiction Hypothesis in Turkish Cigarette and Alcohol Consumption. Addicta: The Turkish Journal on Addictions 2018;5(1):55-65.

6. Mercan S, Onaran OI, Ilbak A, Atasoy H, Teloğlu ES, Torun P, et al. Alkol Tüketim Kültürü ve Alkol Araştırmaları ile Alkol Kontrol Politikaları Konusunda Görüşler: Nitel Bir Araştırma. Addicta: The Turkish Journal on Addictions 2018;5(3):473-505.

7. van der Waal I. Potentially malignant disorders of the oral and oropharyngeal mucosa; terminology, classification and present concepts of management. Oral Oncol 2009;45(4-5):317-23.

8. Warnakulasuriya S, Johnson NW, van der Waal I. Nomenclature and classification of potentially malignant disorders of the oral mucosa. J Oral Pathol Med 2007;36:575-80. [CrossRef]

9. Scully C, Bagan JV, Hopper C, Epstein JB. Oral cancer: current and future diagnostic techniques. Am J Dent 2008;21(4):199209.

10. Parakh MK, Ulaganambi S, Ashifa N, Premkumar R, Jain AL. Oral potentially malignant disorders: clinical diagnosis and current screening aids: a narrative review. Eur J Cancer Prev 
2020;29(1):65-72. [CrossRef]

11. Canova C, Richiardi L, Merletti F, Pentenero M, Gervasio C, Tanturri $G$, et al. Alcohol, tobacco and genetic susceptibility in relation to cancers of the upper aerodigestive tract in northern Italy. Tumori 2010;96(1):1-10. [CrossRef]

12. Pelucchi C, Tramacere I, Boffetta P, Negri E, La Vecchia C. Alcohol consumption and cancer risk. Nutr Cancer 2011;63:98390. [CrossRef]

13. Shield KD, Ferlay J, Jemal A, Sankaranarayanan R, Chaturvedi AK, Bray F, et al. The global incidence of lip, oral cavity, and pharyngeal cancers by subsite in 2012. CA Cancer J Clin 2017;67:51-64. [CrossRef]

14. Warnakulasuriya S. Global epidemiology of oral and oropharyngeal cancer. Oral Oncol 2009;45:309-16. [CrossRef]

15. Llewellyn CD, Johnson NW, Warnakulasuriya KA. Risk factors for squamous cell carcinoma of the oral cavity in young people - a comprehensive literature review. Oral Oncol 2001;37:401-18. [CrossRef]

16. Nowosielska-Grygiel J, Owczarek K, Bielińska M, Wacławek $M$, Olszewski J. Analysis of risk factors for oral cavity and oropharynx cancer in the authors' own material. Otolaryngol Pol 2017;71:23-28. [CrossRef]

17. Franceschi $S$, Talamini R, Barra S, Barón AE, Negri E, Bidoli E, et al. Smoking and drinking in relation to cancers of the oral cavity, pharynx, larynx, and esophagus in northern Italy. Cancer Res 1990;50:6502-7.

18. O'Connor TE, Papanikolaou V, Keogh IJ. Public knowledge of head and neck cancer. Ir Med J 2010;103:105-7.

19. Hertrampf K, Wenz HJ, Koller M, Wiltfang J. Public awareness about prevention and early detection of oral cancer: a population-based study in Northern Germany. J Craniomaxillofac Surg 2012;40:e82-6. [CrossRef]

20. Peker I, Alkurt MT. Public awareness level of oral cancer in a group of dental patients. J Contemp Dent Pract 2010;11:04956. [CrossRef]

21. Srikanth Reddy B, Doshi D, Padma Reddy M, Kulkarni S, Gaffar A, Ram Reddy V. Oral cancer awareness and knowledge among dental patients in South India. J Craniomaxillofac Surg 2012;40:521-4. [CrossRef]

22. Epstein JB, Güneri P. The adjunctive role of toluidine blue in detection of oral premalignant and malignant lesions. Curr Opin Otolaryngol Head Neck Surg 2009;17:79-87. [CrossRef]

23. Keshavarzi M, Darijani M, Momeni F, Moradi P, Ebrahimnejad H, Masoudifar A, et al. Molecular Imaging and Oral Cancer Diagnosis and Therapy. J Cell Biochem 2017;118:3055-60. [CrossRef] 